\title{
Predation and infanticide influence ideal free choice by a parrot occupying heterogeneous tropical habitats
}

\author{
Timothy C. Bonebrake $\cdot$ Steven R. Beissinger
}

Received: 14 April 2009/Accepted: 11 January 2010/Published online: 5 February 2010

(C) The Author(s) 2010. This article is published with open access at Springerlink.com

\begin{abstract}
The ideal free distribution (IFD) predicts that organisms will disperse to sites that maximize their fitness based on availability of resources. Habitat heterogeneity underlies resource variation and influences spatial variation in demography and the distribution of populations. We relate nest site productivity at multiple scales measured over a decade to habitat quality in a box-nesting population of Forpus passerinus (green-rumped parrotlets) in Venezuela to examine critical IFD assumptions. Variation in reproductive success at the local population and neighborhood scales had a much larger influence on productivity (fledglings per nest box per year) than nest site or female identity. Habitat features were reliable cues of nest site quality. Nest sites with less vegetative cover produced greater numbers of fledglings than sites with more cover. However, there was also a competitive cost to nesting in high-quality, low-vegetative cover nest boxes, as these sites experienced the most infanticide events. In the lowland local population, water depth and cover surrounding nest sites were related with $F$. passerinus productivity. Low vegetative cover and deeper water were associated with lower predation rates, suggesting that predation could be a primary factor driving habitat selection patterns. Parrotlets
\end{abstract}

Communicated by Christopher Johnson.

T. C. Bonebrake · S. R. Beissinger

Ecosystem Sciences Division,

Department of Environmental Science,

Policy, and Management, University of California,

37 Mulford Hall, Berkeley, CA 94720-3114, USA

Present Address:

T. C. Bonebrake $(\square)$

Department of Biology, Stanford University,

371 Serra Mall, Stanford, CA 94305-5020, USA

e-mail: tcbone@stanford.edu also demonstrated directional dispersal. Pairs that changed nest sites were more likely to disperse from poor-quality nest sites to high-quality nest sites rather than vice versa, and juveniles were more likely to disperse to, or remain in, the more productive of the two local populations. Parrotlets exhibited three characteristics fundamental to the IFD: habitat heterogeneity within and between local populations, reliable habitat cues to productivity, and active dispersal to sites of higher fitness.

Keywords Ideal free distribution - Habitat selection . Parrot · Dispersal · Infanticide

\section{Introduction}

Animals should select locations in which to reproduce based on how their fitness is likely to vary with habitat features and resource availability. The ideal free distribution (IFD) is one model of how animals will distribute themselves in heterogeneous habitats and predicts that organisms will aggregate in sites proportional to their quality. Specifically, individuals should preferentially settle in high-quality, resource-abundant sites before choosing lower quality, resource-scarce sites (Fretwell and Lucas 1970; Haugen et al. 2006; Morris 2006). There are, however, a number of assumptions of IFD theory that are difficult to test in nature. One is that animals are "ideal" and can accurately assess site quality, and another is that animals are "free" and can disperse without cost to the sites that they deem most suited to maximizing their fitness.

The IFD assumes heterogeneity in habitat quality results in differences in fitness across space. Spatial variation in resource quality can lead to habitat selection at multiple 
spatial scales, from the selection of territories or home ranges within landscapes or populations at larger scales to the choice of nest sites within territories or home ranges at smaller scales (Wiens 1989; Jones 2001; Chalfoun and Martin 2007). When differences in resource quality among populations translate into differences in demographic rates, spatially structured population dynamics may result (Holt 1985; Morris 2003), possibly producing population sources and sinks (Pulliam 1988; Dias 1996; Runge et al. 2006). However, similar processes could also occur at smaller scales within populations, creating more complicated spatial patterns of local variation in fitness.

The "ideal" property of the IFD is the supposition that animals can recognize and choose territories or nest sites within a landscape based on predictable differences in resource quality that are reliably translated into fitness consequences. Thus, variation in fitness must be linked to identifiable habitat features, and individuals should use these cues to move from sites of lower to higher potential fitness (Cody 1985; Clark and Shutler 1999; Morris 2003). The processes that cause fitness heterogeneity could be varied, ranging from differences in food availability (as originally formulated for IFD; Fretwell and Lucas 1970), predation, or microclimate. However, the fitness consequences of habitat selection may be difficult to detect if they are obscured by variation in the quality of individuals choosing sites (Balbontín and Ferrer 2008) or by the different scales at which the habitat selection takes place (Jones 2001).

Density-dependent feedback via interference competition for nest sites or territories may reduce the fitness benefits of high-quality sites. This could lead to a violation of the "free" assumption of the IFD if, for example, competitively superior animals prevent the settlement of others and monopolize high-quality habitat. However, demonstrating mechanistic density-dependent processes in natural populations is not a trivial task (Carrete et al. 2008). Occupancy of low-quality sites may be the result of imperfect habitat selection decisions rather than competitive exclusion from high-quality sites (van Horne 1983; Johnson 2007). Moreover, habitat selection decisions, dispersal patterns, and habitat quality may interact, confounding one another to produce complicated distribution patterns (Davis and Stamps 2004). Therefore, analyses should strive to connect demographic effects, habitat selection and heterogeneity, scale, and competitive processes to mechanistically understand the drivers of animal distributions.

We examine the role of habitat heterogeneity in determining reproductive consequences, dispersal, and intraspecific competition in the green-rumped parrotlet (Forpus passerinus Linnaeus) in Venezuela. We first partition the influences of different scales, from local population to neighborhood to nest to individual, on variation in the productivity of nest sites and identify the demographic mechanisms responsible based on a decade of study. We next examine whether variation in productivity of nest sites is linked to predictable cues in habitat quality or heterogeneity. We then determine if juvenile and adult parrotlets disperse from low- to high-quality nesting sites. Finally, we quantify whether intraspecific competition for high-quality nest sites reduced reproductive success. Our results examine some of the fundamental assumptions of the IFD and indicate that there is large variation in quality among nest sites (habitat heterogeneity), that habitat variation provides reliable cues to nest site quality, and that parrotlets move to and compete most strongly for higher quality sites (i.e., parrotlets are "ideal"). Finally, we explore processes that may influence parrotlet ideal free decisions, primarily predation and infanticide.

\section{Materials and methods}

Study species and field methods

We studied parrotlets at Hato Masaguaral $\left(8^{\circ} 34^{\prime} \mathrm{N}\right.$, $67^{\circ} 35^{\prime} \mathrm{W}$ ) in the Venezuelan llanos, a seasonal savanna with distinct wet and dry periodicity (Troth 1979). F. passerinus is a small (24-36 g) sexually dimorphic parrot that feeds primarily on the seeds of grasses and forbs, including Croton hirtus and Hyptis suaveolens (Beissinger 2008). Breeding occurs during the wet season (MayDecember) in cavities, tree holes, or fence posts (Waltman and Beissinger 1992). In 1988 and 1989, one hundred and six identical nest boxes, made of polyvinyl chloride (Beissinger and Bucher 1992), were installed about 10$20 \mathrm{~m}$ apart along fence lines in two local populations (upland and lowland; Beissinger 2008) separated by 0.5 $0.7 \mathrm{~km}$ of dense forest that is not inhabited by parrotlets (Fig. 1). Parrotlets nest semi-colonially or in isolation, defending only the area immediately adjacent to the nest box, and the distance between boxes was based on observations from simultaneously active nests in natural cavities (Beissinger and Bucher 1992). Nearly all nesting attempts in these populations occurred in nest boxes (Stoleson and Beissinger 2001). Adults have extremely strong philopatry to the local population (hereafter "population") in which they have settled, but movement of dispersing juveniles between the two populations is more common (Beissinger 2008). Demography can also differ significantly between populations; for example, female survival is greater in the upland than in the lowland (Veran and Beissinger 2009). Parrotlets stay within their local population to forage, feeding near nest boxes but ranging up to $1 \mathrm{~km}$ away in search of seeds. 


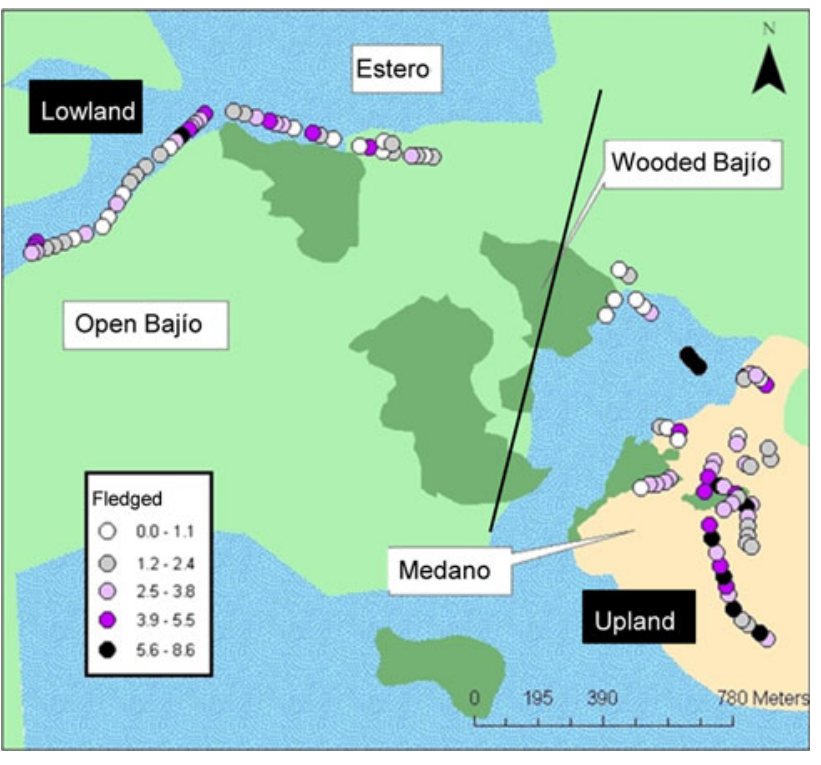

Fig. 1 Map of the study site showing each Forpus passerinus nest box in relation to the landscape habitat features. Shading of nest boxes corresponds to the number of young fledged per year. Nest boxes in the right half of the figure represent the upland population, while those in the left half represent the lowland population

The upland and lowland parrotlet populations inhabit very different habitats. Troth (1979) described four different habitats that comprise the Venezuelan llanos: medano (sandhills), estero (seasonal deeply flooded savanna), wooded bajío (seasonal moderately flooded savanna), and open bajío. The upland consists of primarily medano habitat while the lowland is a matrix of bajio and estero (Fig. 1). During the nesting season, the upland is typically much drier and has little canopy compared to the more flooded and foliage-dense lowland. See Beissinger (2008) for an aerial photograph of the populations and their habitats.

Nest contents were checked every 1-3 days during the breeding season. Parrotlet parents and non-breeders were captured with mistnets, and banded with individually identifiable color bands and a numbered aluminum band (Beissinger 2008). Likewise, all nestlings were ringed with individually identifiable combinations of colored and numbered stainless steel bands (Stoleson and Beissinger 1997). Resightings of color-banded birds were made daily using spotting scopes and binoculars throughout the 6month breeding season (Sandercock et al. 2000; Veran and Beissinger 2009). Strong intraspecific and interspecific competition for nest boxes and a high proportion of nonbreeding birds in both populations suggest that nest site availability is an important factor limiting population growth (Beissinger et al. 1998; Beissinger 2008; Veran and Beissinger 2009).
Estimating productivity and its components at multiple scales

We estimated productivity for each nest box using data collected from 1994 to 2003. These years were chosen because little or no experimental manipulation occurred to confound analyses. For each nest box we calculated productivity (the number of young fledged per year), which is the product of three components: the number of nesting attempts per year, probability of producing a successful nest, and number of fledglings per successful nest. For each nest box, we also calculated rates of nest predation, and interference competition from conspecifics as the total number of infanticide events and nest abandonments due to conspecific harassment. Predation and infanticide events were easily distinguished (Stoleson and Beissinger 2001). The nest boxes are 1-m deep and parrotlets use their bill for climbing, so items cannot be removed from the nest by parrotlets. Nests were considered depredated if all nest contents disappeared between nest checks, or when a snake or rodent was found in a box that previously had chicks or eggs. Infanticide (including egg destruction) was determined from characteristic triangular bite marks on eggs or nestlings made by parrotlet bills (Waltman and Beissinger 1992; Beissinger et al. 1998; Stoleson and Beissinger 2001). Sometimes infanticide leading to nest mortality was caused when conspecifics harassed (through vigorous displaying, fighting and vocalizing) a pair or lone female to abandon a nest with eggs or chicks (Waltman and Beissinger 1992).

We also examined productivity at the population and neighborhood scales. Each nest box was located in either the upland or lowland population (Beissinger 2008), and in a neighborhood, which was classified by the spatial proximity and clustering of other nest boxes and by the relative homogeneity of habitat surrounding them. These neighborhoods consisted of three to 13 nest boxes, and represented our best assessment of which pairs at nest boxes interacted most with one another based on a decade of daily observations of banded individuals. The neighborhood scale was in tens of meters range, which is often designated as the scale at which neighbors interact (Canham et al. 2006; Potvin and Dutilleul 2009). Parrotlet neighbors interact through territorial displays, intrusions at nest sites, and foraging flocks (Waltman and Beissinger 1992; Beissinger 2008). Forty-five nest boxes were partitioned among five lowland neighborhoods and 61 nest boxes among ten upland neighborhoods.

\section{Habitat characterization}

Habitat measures were made from June to August 2004 at nest boxes and in their surrounding neighborhoods. Since all boxes had equal dimensions and were placed at similar 
heights above ground (Beissinger and Bucher 1992), these characteristics were not analyzed. At each box, estimates of both vertical and horizontal components of vegetation cover were made by placing a pole vertically into the vegetation. Vertical cover was estimated around each nest site by recording the height at which each plant struck the pole, and horizontal cover by placing a small grid $(85 \mathrm{~mm}$ by $85 \mathrm{~mm}$ ) made of hardware cloth with 100 squares on the ground (through grasses and plants with vertical structure), and counting the number of squares with vegetation to yield a percent cover. Canopy cover was calculated by holding the grid overhead with extended arms and counting the number of quads with cover. Vegetation measurements were made at 12 points at each nest box $(0.5,5$, and $10 \mathrm{~m}$ from the box for each of the four cardinal compass directions). Food abundance was estimated by placing a $0.75-\mathrm{m}$ diameter hoop and counting seeds of the main food plants (Croton sp. and Hyptis sp.) within the hoop (Stoleson and Beissinger 1997). We also measured water depth and estimated the percent water cover with the $85 \mathrm{~mm} \times 85 \mathrm{~mm}$ grid at each of the 12 sampling points.

\section{Data analysis}

A nested ANOVA of the number of young fledged per year and its three productivity components assessed differences in variation evident at each scale: female identity, box, neighborhood, and population. The female identity (ID) term was nested within box to determine how variation among females affected productivity. Females usually nest in only one box annually, supporting the nested design. When more than one female nested in a box in a year, we used the first female as the ID term. The number of young fledged per successful nest did not include the female ID because cells with no data (i.e., no nests or unsuccessful nests) were too numerous for a meaningful analysis.

Habitat measures (canopy cover; ground cover; water cover; water depth; Croton stems; Croton pods; non-Croton stems; and vegetation counts grouped into intervals of $0-0.5,0.5-1,1-1.5$, and $1.5-2 \mathrm{~m}$ above ground) were either $\log +1$ or arcsin transformed, and then analyzed using a principal component analysis (PCA). Habitat variables were reduced to three components from PCA, accounting for $64.9 \%$ of the total variation (Table 1 ). Principal components at the box scale consisted of a factor characterizing the water and ground vegetation (Water), Croton/food density (Croton), and ground and canopy cover (Canopy). Habitat factors described by the PCA were then analyzed as covariates in an analysis of covariance (ANCOVA) with population (upland or lowland) as the grouping factor to find the effect on site productivity. To explore the relationship between habitat and infanticide, we grouped nest boxes by the number of nest mortality
Table 1 Principal component $(P C)$ analysis loadings of habitat variables and the percentage of variance it explains in parentheses

\begin{tabular}{|c|c|c|c|}
\hline & \multicolumn{3}{|l|}{ Box scale } \\
\hline & PC1 Water & PC2 Croton & PC3 Canopy \\
\hline Habitat component & $(35.9)$ & $(16.8)$ & $(12.2)$ \\
\hline Canopy cover & 0.12 & 0.40 & 0.75 \\
\hline Water cover & -0.87 & 0.30 & 0.11 \\
\hline Ground cover & 0.76 & 0.34 & 0.13 \\
\hline Water depth & -0.88 & 0.30 & 0.12 \\
\hline Veg. count $0-0.5 \mathrm{~m}$ & 0.64 & -0.49 & -0.07 \\
\hline Veg. count $0.5-1 \mathrm{~m}$ & -0.48 & 0.08 & 0.14 \\
\hline Veg. count $1-1.5 \mathrm{~m}$ & -0.37 & 0.00 & 0.43 \\
\hline Veg. count $1.5-2 \mathrm{~m}$ & -0.36 & 0.17 & 0.61 \\
\hline Croton stem count & 0.15 & -0.91 & -0.01 \\
\hline Croton pod count & 0.16 & -0.88 & -0.13 \\
\hline Hyptis stem count & 0.00 & -0.12 & 0.71 \\
\hline
\end{tabular}

Loadings greater than 0.5 are shown in bold

Veg. vegetation

events caused by conspecifics $(0,1, \geq 2)$. We then used an ANOVA to test the effect of habitat on infanticide.

Dispersal data based on resightings of color-banded birds were analyzed to determine if pairs or males were more likely to move to nest sites with higher or lower quality using a $\chi^{2}$ test. We did not repeat this test for females because pairs mate for life and males choose nest sites (Waltman and Beissinger 1992; Beissinger 2008), so the results would have been duplicative. We used productivity data collected from 1994 to 2003 to derive a measure of site quality and dispersal data from 2004 to 2005 , so that measures of nest site quality would be independent of the quality of the dispersing individuals. We ran similar analyses to determine if dispersal was related to habitat quality of nest sites using each box's PCA score.

\section{Results}

At what spatial scales do differences in reproductive success exist?

Reproductive success varied greatly among boxes (Fig. 1; Table 2). The average number of young fledged per year per box ranged from zero to over eight. Some boxes were used every year and received two or three nests per year, while other boxes had nests in only $30 \%$ of the years. The probability of producing a successful nest at a box also varied greatly among boxes from 0 to 0.93 . Less variation among boxes occurred in the number of young fledged per successful nest than other measures of box quality. Components of productivity were not independent of each other 
(Table 2): the number of nesting attempts, fledglings per successful nest, and the probability of having a successful nest were strongly related to each other and to the number of young fledged per year. Thus, we concentrated our analysis on the number of young fledged per year per box, which may be the best measure of potential quality of nest sites and the contribution of nest sites to population growth.

Variation in reproductive success among nest boxes was most strongly attributed to local population and neighborhood scales (Table 3). The number of young fledged per box per year was significantly greater in the upland than in the lowland population (Table 3 ) and also differed strongly among neighborhoods, as suggested by the clumped distribution of highly productive boxes within each population in Fig. 1. Once population and neighborhood scales were accounted for, variation was less pronounced among nest boxes and was unaffected by variation among females. However, other components of reproductive success, such as the number of nesting attempts, depended on nest box and individual variation as well as the population and neighborhood level (Table 3).

Are there predictable habitat cues

to high- and low-quality nest sites?

Two habitat characteristics provided reliable cues about the quality of nest boxes. First, water PCA scores (higher Water indicating higher water cover and depth) interacted with population (ANCOVA: Water PCA, $F=0.02$, $P=0.88$; Population, $F=5.18, \quad P=0.03$; Water PCA $\times$ Population interaction, $F=5.60, P=0.02)$ and were associated with greater productivity (fledged/year) in the lowland (Fig. 2a). This association was absent in the upland, likely due to the dry conditions at nearly all sites here (Fig. 2a). Second, Canopy PCA scores (higher Canopy indicating higher canopy cover) were significantly negatively related with productivity (ANCOVA: Canopy
PCA, $\quad F=18.11, \quad P<0.001 ; \quad$ Population, $\quad F=0.50$, $P=0.48$ ); boxes that had higher Canopy PCA scores generally fledged fewer nestlings than those with lower scores in both populations (Fig. 2b). Nest predation appears partly responsible for these relationships. Predation rates decreased with water PCA scores (Fig. 2c; ANCOVA: Water PCA, $F=4.80, P=0.03$; Population, $F=7.02, P=0.009)$ and increased with neighborhood canopy cover for the lowland population (Fig. 2d; ANCOVA: Canopy PCA, $F=1.12, P=0.27$; Population, $F=1.23, P=0.27$; Canopy PCA $\times$ Population interaction, $F=8.47, P=0.004)$. Also predation rate was higher in the lowland compared to the upland, although the local population effect on predation rate was only marginally significant (ANOVA: $F=3.03, P=0.09$ ). Local measures of food abundance (Croton PCA scores) were much greater in the upland and were negatively related with the number of young fledged per year in the lowland, but were unrelated to productivity in the upland (ANCOVA: Population, $F=7.80, P=0.006$; Croton PCA, $F=3.73$, $P=0.06$; Population $\times$ Croton $\quad$ PCA interaction, $F=4.64, P=0.03)$.

Is the intensity of interference competition related to nest site quality?

Higher quality nest sites were monopolized first and experienced stronger intraspecific competition in the form of infanticide attacks than lower quality sites. The most productive boxes were occupied earlier in the season than less productive boxes (Fig. 3). Moreover, parrotlets competed more intensely for nest sites with less canopy cover, which were also associated with greater productivity. The chance of infanticide attacks by other parrotlets was significantly greater in boxes in more open areas (ANOVA, $F=5.87, d f=2, P=0.004)$ than in boxes with greater canopy cover (Fig. 4).

Table 2 Summary statistics and relationships between components of Forpus passerinus productivity at 106 nest boxes from 1994 to 2003

\begin{tabular}{|c|c|c|c|c|c|c|c|c|}
\hline \multirow{2}{*}{$\begin{array}{l}\text { Productivity } \\
\text { components }\end{array}$} & \multirow[t]{2}{*}{$\bar{x} \pm \mathrm{SE}$} & \multirow[t]{2}{*}{ Range } & \multirow{2}{*}{$\begin{array}{l}\text { Upland } \\
(\bar{x} \pm \mathrm{SE})\end{array}$} & \multirow{2}{*}{$\begin{array}{l}\text { Lowland } \\
(\bar{x} \pm \mathrm{SE})\end{array}$} & \multicolumn{4}{|c|}{ Correlation coefficient $(r)$} \\
\hline & & & & & $\begin{array}{l}\text { Years } \\
\text { used }\end{array}$ & $\begin{array}{l}\text { Probability of } \\
\text { successful } \\
\text { nest }\end{array}$ & $\begin{array}{l}\text { Fledged/ } \\
\text { successful } \\
\text { nest }\end{array}$ & $\begin{array}{l}\text { Nesting } \\
\text { attempts }\end{array}$ \\
\hline Young fledged/year & $2.9 \pm 0.2$ & $0-8.6$ & $3.2 \pm 0.3$ & $2.4 \pm 0.2$ & $0.76 * *$ & $0.65 * *$ & $0.25 * *$ & $0.79 * *$ \\
\hline Nesting attempts/year & $1.2 \pm 0.5$ & $0.3-2.6$ & $1.3 \pm 0.7$ & $1.0 \pm 0.8$ & $0.92 * *$ & $0.32 * *$ & 0.03 & - \\
\hline $\begin{array}{l}\text { Young fledged/ } \\
\text { successful nest }\end{array}$ & $4.5 \pm 0.02$ & $2.6-6.3$ & $4.4 \pm 0.1$ & $4.6 \pm 0.1$ & -0.04 & $0.12 *$ & - & - \\
\hline $\begin{array}{l}\text { Probability of successful } \\
\text { nest }\end{array}$ & $0.48 \pm 0.1$ & $0-0.93$ & $0.46 \pm 0.03$ & $0.49 \pm 0.03$ & 0.30 & - & - & - \\
\hline Years used & $7.1 \pm 0.2$ & $3-10$ & $7.5 \pm 0.3$ & $6.5 \pm 0.4$ & - & - & - & - \\
\hline
\end{tabular}

$* P<0.05, * * P<0.001$ 
Table 3 Nested ANOVAs of productivity measures for $F$. passerinus apportioned among different scales

\begin{tabular}{|c|c|c|c|c|c|}
\hline Productivity components & Scale & $d f$ & Mean square error & $F$-ratio & $P$ \\
\hline \multirow[t]{5}{*}{ Young fledged/year } & Population & 1 & 158.94 & 11.43 & $\leq 0.001$ \\
\hline & Neighborhood (Population) & 13 & 91.83 & 6.60 & $\leq 0.001$ \\
\hline & Nest box (Neighborhood) & 91 & 17.71 & 1.27 & $\leq 0.110$ \\
\hline & Female ID (Nest box) & 839 & 12.01 & 0.86 & $\leq 0.865$ \\
\hline & Error & 115 & 13.91 & & \\
\hline \multirow[t]{5}{*}{ Nesting attempts/year } & Population & 1 & 13.81 & 38.58 & $\leq 0.001$ \\
\hline & Neighborhood (Population) & 13 & 7.89 & 22.04 & $\leq 0.001$ \\
\hline & Nest box (Neighborhood) & 91 & 2.07 & 5.78 & $\leq 0.001$ \\
\hline & Female ID (Nest box) & 839 & 0.73 & 2.05 & $\leq 0.001$ \\
\hline & Error & 115 & 0.36 & & \\
\hline \multirow[t]{5}{*}{ Probability of nesting successfully } & Population & 1 & 1.45 & 10.33 & $\leq 0.002$ \\
\hline & Neighborhood (Population) & 13 & 0.91 & 6.50 & $\leq 0.001$ \\
\hline & Nest box (Neighborhood) & 91 & 0.25 & 1.80 & $\leq 0.001$ \\
\hline & Female ID (Nest box) & 839 & 0.17 & 1.19 & $\leq 0.120$ \\
\hline & Error & 115 & 0.14 & & \\
\hline \multirow[t]{4}{*}{ Young/successful nest } & Population & 1 & 0.36 & 0.11 & $\leq 0.741$ \\
\hline & Neighborhood (Population) & 13 & 5.37 & 1.62 & $\leq 0.083$ \\
\hline & Nest box (Neighborhood) & 91 & 3.34 & 1.01 & $\leq 0.470$ \\
\hline & Error & 363 & 3.32 & & \\
\hline
\end{tabular}

$I D$ identity

Do individuals move from low- to high-quality nest sites?

Two forms of evidence suggest that parrotlets move from nest sites and populations with lower productivity to those with higher productivity. At the nest box scale, pairs that changed nests boxes in 2004 and $2005(n=32)$ were significantly more likely $\left(\chi^{2}=4.5, d f=1, P=0.03\right)$ to select a new box that had fledged a greater number of young annually in previous years $(69 \%)$ than a box with lower or equal fitness $(31 \%)$. The median increase in box quality was 0.8 young per year. Whether the male nested at the new box with his original mate or had taken a new mate, or whether the box change occurred within or between years did not significantly affect the direction of change in nest box quality (logistic regression, $d f=2, P=0.836$ ). Parrotlets tended to disperse to sites with lower $(63 \%)$ rather than higher canopy cover $(37 \%)\left(\chi^{2}=2.0, d f=1, P=0.15\right)$. However, when considering only large $(>1)$ changes in the Canopy PCA score, parrotlets were significantly more likely to disperse to boxes with less canopy $(n=11$, $\left.\chi^{2}=4.5, d f=1, P=0.03\right)$. Parrotlets did not appear to preferentially disperse to nest boxes with higher or lower water cover $\left(\chi^{2}=0.0, d f=1, P=1.0\right)$.

Considering movement at the population scale, juvenile parrotlets were significantly more likely to settle in the population with greater productivity $\left(\chi^{2}=204.5, d f=1\right.$,
$P<0.001)$. Upland juveniles $(n=711)$ were more likely to remain in the upland $(84.2 \%)$ rather than to disperse to the lowland (15.8\%), while lowland juveniles $(n=381)$ were almost as likely to move to the upland $(42.5 \%)$ as they were to remain in the lowland $(57.5 \%)$.

\section{Discussion}

Habitat quality is best measured by habitat-specific demography (Johnson 2007). However, inference of habitat quality depends upon the scale and level of demographic analysis (Pidgeon et al. 2006). When we partitioned reproductive success among separate but nested scales, variation was attributable to nest box, neighborhood, and population scales, and also to variation in individual quality (Table 3). This resulted in a "lumpy" landscape (Fig. 1), with higher and lower quality sites and neighborhoods located within populations that also differed in quality. The best sites and neighborhoods in the less productive lowland population were as productive as their counterparts in the more productive upland. Moreover, variation in individual or female quality mediated differences among sites, neighborhoods and populations, further complicating the fitness landscape and habitat selection decisions.

Habitat determinants of reproductive success were clearly evident (Fig. 2). Higher vegetative cover was 
Fig. 2 Relationships of habitat measures at the box scale with productivity and rates of predation. The number of young fledged per year versus principal component scores for measures of water (a) and canopy (b). Predation rate is shown as a function of water (c) and canopy (d). The upland population is portrayed by open circles and a dotted regression line, and the lowland population is shown by filled circles and a solid regression line
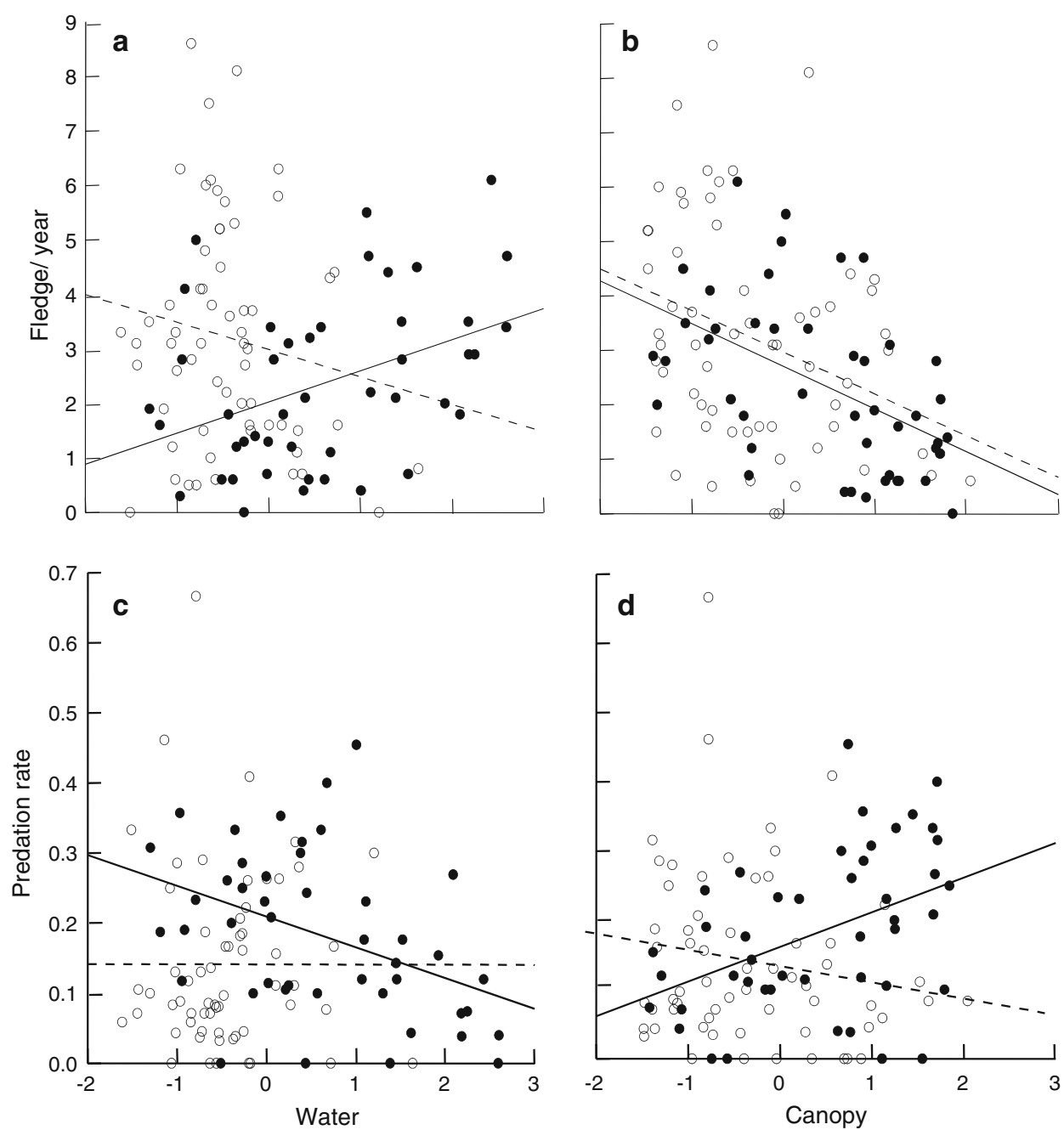

associated with lower productivity at nest sites in both populations. Predation is probably an important cause of

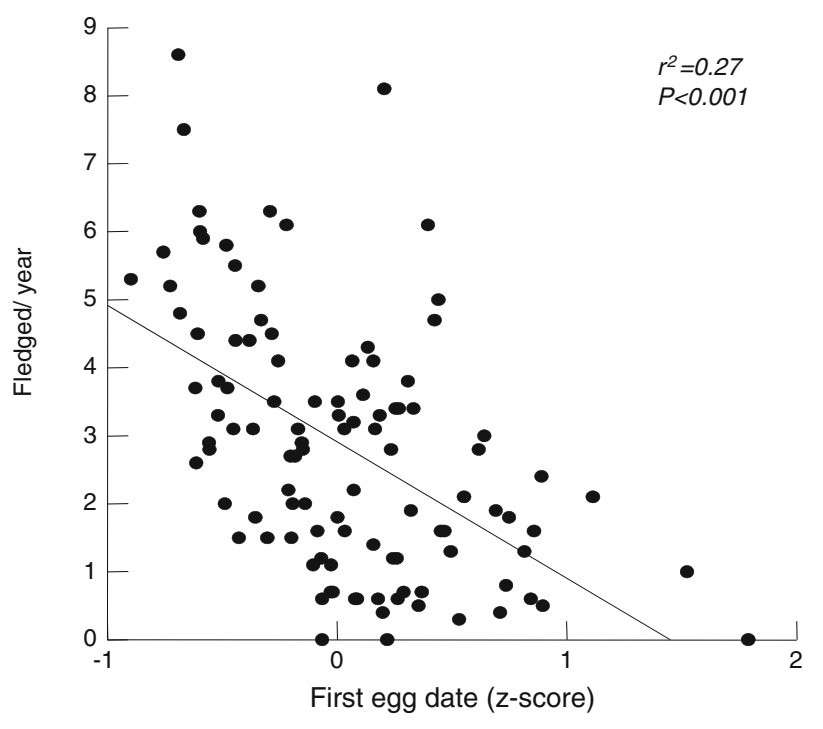

Fig. 3 The effect of standardized first egg date on the number of young fledged per year this result. Higher rates of predation were associated with greater vegetative cover in the lowland but not in the upland population (Fig. 2). Nest predators are typically more common in forested areas comprising the lowland at our study site (Eisenberg 1979). The benefit of a decreased risk of predation by nesting in a box with less vegetation was partly reduced by infanticide, which occurred more often at less vegetated sites (Fig. 4). Infanticide occurred more often in the upland than in the lowland population, which may have accounted for differences in the effect of predation between these two populations. Nest boxes were also more productive when surrounded by standing water in the lowland but not in the upland. Deep water deters nest predators (Collias and Collias 1984; Leonard and Picman 1987; Jobin and Picman 1997). Water may not have exerted strong effects on upland productivity because ground elevation is high enough that standing water during the rainy season never reaches most upland nest sites (Fig. 1), even in the rainiest years. Nevertheless, local food 


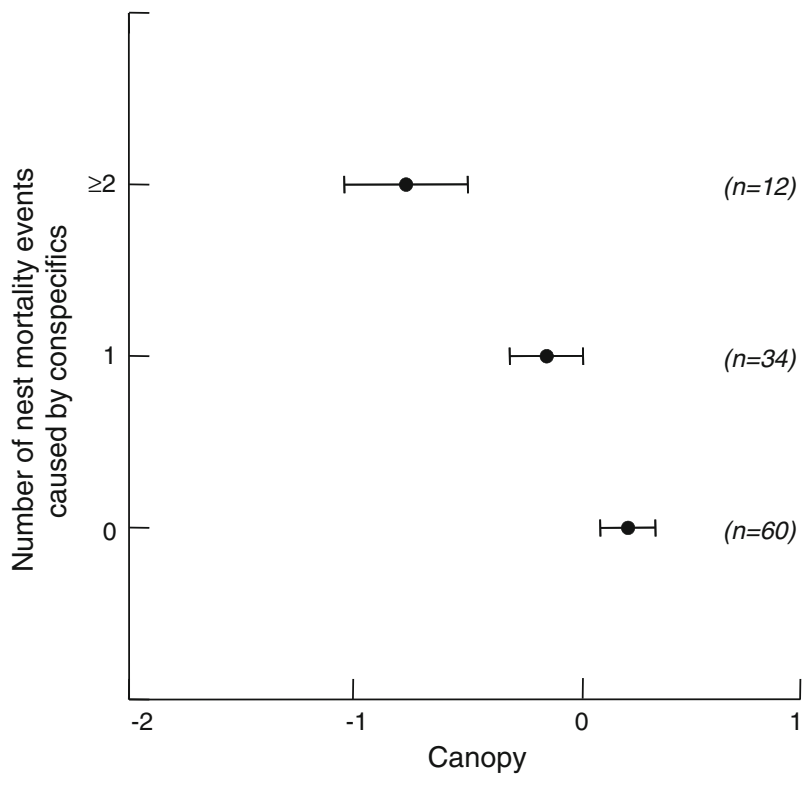

Fig. 4 Nest boxes with zero, one, and more than two infanticide events (or abandonment resulting from conspecific harassment) during the study period in relation to the average (and SE) canopy principal component analysis score

(seed) abundance was unrelated to productivity, suggesting that either it is not an important factor or it acts at larger spatial scales. Starvation commonly causes brood reduction in parrotlets, which results in an unequal distribution of food among nestlings of tremendously different size and competitive ability rather than a shortage of food, but rarely causes complete nest failure (Stoleson and Beissinger 1997; Budden and Beissinger 2009).

Some inaccuracies in the relationship between habitat cues and productivity are introduced by comparing habitat conditions measured in 2004 to productivity estimates made from 1994 to 2003. However, changes to the llanos habitats around parrotlet nest sites over this time period were not large. Vegetative cover adjacent to nest sites experienced only minor changes, although the canopy has become more closed in the forests surrounding the lowland. Annual variation in rainfall is large and would affect measures of water depth made in 2004. However, relative differences in water depth among nest sites should remain the same.

Movements of adults within populations and dispersal of juveniles between populations indicate that parrotlets may identify habitat cues related to high-quality nest sites and preferentially disperse to them. Parrotlet pairs generally have high nest site fidelity (Waltman and Beissinger 1992) and adults rarely move between populations after they have initiated breeding (Sandercock et al. 2000; Beissinger 2008). When adults did change nest boxes, they more often chose boxes in their population with greater productivity. Moreover, parrotlets disperse primarily as juveniles and juvenile dispersers preferentially chose to settle in the population with higher productivity (the upland). These results are compatible with several prevailing models of population distribution, as discussed below.

Parrotlet adult and juvenile dispersal patterns meet two important assumptions underlying IFD theory (Fretwell and Lucas 1970). Variation in habitat quality is at least partially predictable, since nest sites in the open and with more water experienced less predation than boxes with vegetation cover, near forested habitats, and with less water. Also, parrotlets dispersed preferentially to nest boxes with higher productivity (i.e., quality). Under these conditions that are characteristic of "ideal animals", population distributions should become evolutionary stable and converge to an IFD (Cressman and Křivan 2006). However, predator-prey dynamics have the potential to disrupt IFD (Abrams 2007). Multiple predators prey on parrotlet nests (Stoleson and Beissinger 2001), which may complicate the temporal and spatial dynamics of the parrotlet populations.

Two features of the parrotlet population suggest that preemptive or ideal despotic occupancy may also be occurring (Pulliam and Danielson 1991; Oro 2008). Boxes with nests that were initiated earlier in the season were also the most productive (Fig. 3) and high-quality nest sites experienced elevated intraspecific competition reflected by infanticide attacks (Fig. 4). The patterns of pre-emptive site occupancy and habitat heterogeneity within and between populations prevalent in parrotlets also met two conditions necessary for site-dependent regulation (Rodenhouse et al. 1997). Moreover, as population size increases, parrotlets should increasingly nest in lower quality sites, which will lower overall reproductive success and population growth. Sitedependent regulation is a density-free process, but the spatial constraints prevalent due to limited nesting sites (nest boxes) may facilitate increased infanticide. Rates of infanticide can be positively related to population density (Møller 2004), which appears to occur in parrotlets (unpublished data), but this is not always the case (Boonstra 1980; Rankin and Kokko 2007). Interference competition in the form of infanticide in parrotlets decreases the advantage of nest boxes that are less likely to experience predation (Figs. 2,4).

Our results show that parrotlets meet three important assumptions of the IFD. First, heterogeneity in productivity, or site fitness, existed at multiple scales. Second, productivity varied reliably with habitat quality, providing parrotlets with dependable cues for choosing good sites (e.g., canopy cover and water). Third, parrotlets actively dispersed to sites of higher fitness. Predation and infanticide were important processes that influenced "ideal free" choices, creating spatial structure in productivity within and among parrotlet populations.

Acknowledgments We are indebted to the many tireless Forpus team field assistants over the years, including the 2004 team of Karl 
Berg, Laryssa Ron Esteves, Douglas Schaefer, and Mandy Walker. Cheiko Plotts helped in GIS analyses. We thank the Beissinger lab and two anonymous reviewers for comments on the manuscript. Thanks to the late Tomas Blohm for permission to work and live on his ranch. This research was funded by CNR's UROP (undergraduate research opportunity program), UC Berkeley's URAP (undergraduate research apprentice program), the National Science Foundation (DEB-9503194 and IBN-0113173) and an REU supplement, the National Zoological Park, and the National Geographic Society. The research described here was compliant with the current laws of Venezuela.

Open Access This article is distributed under the terms of the Creative Commons Attribution Noncommercial License which permits any noncommercial use, distribution, and reproduction in any medium, provided the original author(s) and source are credited.

\section{References}

Abrams PA (2007) Habitat choice in predator-prey systems: spatial instability due to interacting adaptive movements. Am Nat 169:581-594

Balbontín J, Ferrer M (2008) Density-dependence by habitat heterogeneity: individual quality vs. territory quality. Oikos 117:1111-1114

Beissinger SR (2008) Long-term studies of the green-rumped parrotlet in Venezuela: hatching asynchrony, social system, and population structure. Ornitol Neotrop 19:73-83

Beissinger SR, Bucher EH (1992) Can parrots be conserved through sustainable harvesting. Bioscience 42:164-173

Beissinger SR, Tygielski S, Elderd B (1998) Social constraints on the onset of incubation in a Neotropical parrot: a nestbox addition experiment. Anim Behav 55:21-32

Boonstra R (1980) Infanticide in microtines: importance in natural populations. Oecologia 46:262-265

Budden AE, Beissinger SR (2009) Resource allocation varies with parental sex and brood size in the asynchronously hatching green-rumped parrotlet (Forpus passerinus). Behav Ecol Sociobiol 63:637-647

Canham CD, Papaik MJ, Uriarte M, McWilliams WH, Jenkins JC, Tweery MJ (2006) Neighborhood analyses of canopy tree competition along environmental gradients in New England forests. Ecol Appl 16:540-554

Carrete M, Tella JL, Sánchez-Zapata JA, Moleón M, Gil-Sánchez JM (2008) Curent caveats and further directions in the analysis of density-dependent population regulation. Oikos 117:1115-1119

Chalfoun AD, Martin TE (2007) Assessments of habitat preference and quality depend on spatial scale and metrics of fitness. J Appl Ecol 44:983-992

Clark RG, Shutler D (1999) Avian habitat selection: pattern from process in nest-site use by ducks? Ecology 80:272-287

Cody ML (1985) Habitat selection in birds. Academic Press, Orlando

Collias NE, Collias EC (1984) Nest building and bird behavior. Princeton University Press, Princeton

Cressman R, Křivan V (2006) Migration dynamics for the ideal free distribution. Am Nat 168:384-397

Davis JM, Stamps JA (2004) The effect of natal experience on habitat preferences. Trends Ecol Evol 19:411-416

Dias PC (1996) Sources and sinks in population biology. Trends Ecol Evol 11:326-330

Eisenberg JF (1979) Vertebrate ecology in the northern neotropics. Smithsonian Institution Press, Washington, DC

Fretwell S, Lucas HJ (1970) On territorial behavior and other factors influencing habitat distribution in birds. I. Theoretical development. Acta Biotheor 19:16-36
Haugen TO, Winfield IJ, Vøllestad LA, Fletcher JM, James JB, Stenseth NC (2006) The ideal free pike: 50 years of fitness maximizing dispersal in Windemere. Proc R Soc B 273: 2917-2924

Holt RD (1985) Population dynamics in 2-patch environments-some anomalous consequences of an optimal habitat distribution. Theor Popul Biol 28:181-208

Jobin B, Picman J (1997) Factors affecting predation on artificial nests in marshes. J Wildl Manage 61:792-800

Johnson MD (2007) Measuring habitat quality: a review. Condor 109:489-504

Jones J (2001) Habitat selection studies in avian ecology: a critical review. Auk 118:557-562

Leonard ML, Picman J (1987) Nesting mortality and habitat selection by marsh wrens. Auk 104:491-495

Møller AP (2004) Rapid temporal change in frequency of infanticide in a passerine bird associated with change in population density and body condition. Behav Ecol 15:462-468

Morris DW (2003) Toward an ecological synthesis: a case for habitat selection. Oecologia 136:1-13

Morris DW (2006) Ecology: moving to the ideal free home. Nature 443:645-646

Oro D (2008) Living in a ghetto within a local population: an empirical example of an ideal despotic distribution. Ecology 89:838-846

Pidgeon AM, Radeloff VC, Mathews NE (2006) Contrasting measures of fitness to classify habitat quality for the black-throated sparrow (Amphispiza bilineata). Biol Conserv 132:199-210

Potvin C, Dutilleul P (2009) Neighborhood effects and sizeasymmetric competition in a tree plantation varying in diversity. Ecology 90:321-327

Pulliam HR (1988) Sources, sinks, and population regulation. Am Nat 132:652-661

Pulliam HR, Danielson BJ (1991) Sources, sinks, and habitat selection-a landscape perspective on population-dynamics. Am Nat 137:S50-S66

Rankin DJ, Kokko H (2007) Do males matter? The role of males in population dynamics. Oikos 116:335-348

Rodenhouse NL, Sherry TW, Holmes RT (1997) Site-dependent regulation of population size: a new synthesis. Ecology 78:20252042

Runge JP, Runge MC, Nichols JD (2006) The role of local populations within a landscape context: defining and classifying source and sinks. Am Nat 167:925-938

Sandercock BK, Beissinger SR, Stoleson SH, Melland RR, Hughes CR (2000) Survival rates of a neotropical parrot: implications for latitudinal comparisons of avian demography. Ecology 81: $1351-1370$

Stoleson SH, Beissinger SR (1997) Hatching asynchrony, brood reduction, and food limitation in a neotropical parrot. Ecol Monogr 67:131-154

Stoleson SH, Beissinger SR (2001) Does risk of nest failure or adult predation influence hatching patterns of the green-rumped parrotlet? Condor 103:85-97

Troth RG (1979) Vegetational types on a ranch in the central llanos of Venezuela. In: Eisenberg JF (ed) Vertebrate ecology in the Northern neotropics. Smithsonian Institution Press, Washington, DC, pp 17-30

Van Horne B (1983) Density as a misleading indicator of habitat quality. J Wildl Manage 47:893-901

Veran S, Beissinger SR (2009) Demographic origins of skewed operational and adult sex ratios: perturbation analyses of two-sex models. Ecol Lett 12:129-143

Waltman JR, Beissinger SR (1992) Breeding behavior of the greenrumped parrotlet. Wilson Bull 104:65-84

Wiens JA (1989) Spatial scaling in ecology. Funct Ecol 3:385-397 